\title{
Development and Validation of Dichotomous Thinking Index for Children
}

\author{
Seon Yeop Kim¹, Seong-hoon Hwang ${ }^{2}$ \\ Teacher, Hakun Elementary School, Gimpo, Korea ${ }^{1}$ \\ Professor, Department of Counseling Psychology, Hanyang Cyber University, Seoul, Korea ${ }^{2}$ \\ 아동용 이분법적 사고 지표의 개발 및 타당화 \\ 김선엽 ${ }^{1}$ 황성훈 ${ }^{2}$ \\ 김포 학운초등학교 교사, 한양사이버대학교 상담심리학과 교수 ${ }^{2}$
}

\begin{abstract}
Objectives: This study was conducted to develop and validate the Dichotomous Thinking Index for Children (DTI-C).

Methods: Data was collected from a sample of 4th, 5th and 6th grade students at elementary schools located in Gyeonggi-do. The preliminary version of the DTI-C contained 18 items and was administered to 271 children. After a series of analyses, 15 items were retained. The validity of these items was cross verified in another 200 children. Data was analyzed through exploratory and confirmatory factor analysis, and a correlation analysis.

Results: Exploratory factor analysis and the following confirmatory factor analysis revealed a fourfactor structure consisting of 'extreme decision', 'success or failure', 'social splitting', and 'dichotomous thinking in verbalization'. Cronbach's $\alpha$ ranged from .85 to .87 , indicating a proper level of internal consistency. Concurrent validity was established through the significant correlation of the DTI-C with measures of depression, anxiety, and self-esteem.

Conclusion: Considering its reliability and validity, the DTI-C developed and evaluated in this study could serve as a useful tool for assessing dichotomous thinking in elementary school students.
\end{abstract}

Keywords: Dichotomous Thinking Index for Children, exploratory factor analysis, confirmatory factor analysis, validation

\section{Introduction}

이분법적 사고란 선택지가 양극단뿐이고 중간지대가 없는 사 고방식이다. 극단적인 판단 경향으로서 이분법적 사고는 우 울, 불안, 정서 기복, 역기능적 완벽주의, 충동성, 섭식 문제, 경 계선 성격 장애 등 다양한 정신병리에서 인지적 취약성으로 작용한다는 것이 성인 대상의 연구에서 밝혀지고 있다(Arntz, 1994; Cohen \& Petrie, 2005; Egan, Piek, Dyck, \& Rees, 2007; Ginsburg \& Opper, 1988/2006; Hwang, 2013; Hwang \& Lee,

Corresponding Author: Seong-hoon Hwang, Professor, Department of Counseling Psychology, Hanyang Cyber University, 220, Wangsimni-ro, Seongdong-gu, Seoul, Korea

E-mail: thinkgrey@hanmail.net
2009; Kang, 2010). 따라서 인지적 왜곡으로서 이분법적 사고 를 평가하고 재구성하는 것은 다양한 정신병리를 포괄하는 범 진단적 인지 치료에 공헌할 수 있다.

이분법적 사고란 상호배타적인 범주로 평가하는 경향으 로서 양분된 범주 사이에는 중간 지대가 존재하지 않는 사고 이다(Beck, Freeman, \& Associates, 1990). 특히 Beck, Weissman, Lester와 Trexler (1976)는 전부가 아니면 전무인 사고(all or nothing thinking)로서 이분법적 사고는 상황을 판단할 때 단 두 개의 범주로 세상을 보며, 언어습관으로는 '항상' '절대

(C)The Korean Association of Child Studies

This is an Open Access article distributed under the terms of the Creative Commons Attribution Non-Commercial License (http:// creativecommons.org/licenses/by-nc/4.0) which permits unrestricted noncommercial use, distribution, and reproduction in any medium, provided the original work is properly cited. 
로', '완벽하게', '전적으로' 등이 자주 출현한다고 하였다. 또한 Beck, Rush, Shaw와 Emery (1979)는 이분법적 사고를 결함 있 는 정보처리의 하나로 분류하고 모든 경험을 연속선상에서 판 단하는 대신 두 개의 정반대 범주 중 하나로 결정하는 인지적 경직성의 한 형태라고 하였다. Linehan (1993)은 '정과 반의 양 극단 사이에서 합을 이루지 못한 사고' 로서, 이분법적 사고에 의지하면, 상호 모순된 관점을 경직되게 유지하되 그 사이를 왔다 갔다 하는 경향을 보인다고 하였다. 세상을 지각하는 인 지적 프레임으로 이분법적 사고가 침식하는 부분이 많을수록 세상은 극단적으로 다가오게 된다(Hwang, 2007).

성인을 대상으로 한 선행연구들에 따르면 이분법적 사 고는 다양한 정신병리에서 인지 매개 요인의 역할을 한다 (Ginsburg \& Opper, 1988/2006; Hwang \& Lee, 2009; Kang, 2010). 이분법적 사고는 경계선 성격에서 인지적 왜곡으로 작 용하고(Arntz, 1994; Hwang \& Lee, 2011; Napolitano \& McKay, 2007), 우울증의 재발을 설명하며(Teasdale et al., 2001), 자살 의 병력을 반영한다(Litinsky \& Haslam, 1998). 또한 이분법 적 사고는 섭식 문제의 심각성을 예측하고(Cohen \& Petrie, 2005), 부정적 완벽주의와 관련 돼(Egan et al., 2007), 신체 감 각을 재앙적 해석으로 증폭시켜 공황 발작을 유발하는 인지 요인으로 작용하고(Hwang \& Lee, 2012), 양극성 장애 성향을 가진 대학생들의 정서적 가변성을 증폭시킨다(Hwang, 2013).

아동을 대상으로 한 인지행동치료에서는 다양한 인지오류 의 하나로서 이분법적 사고가 다뤄지고 있다. 초등학생이 학 업에서 개인화, 재앙화, 과잉 일반화, 선택적 주의 등의 인지 오류를 많이 범할수록 기능적 수행 능력이 저하되고, 우울감 이 야기된다(Bae, 2014). 이러한 오류 중 재앙화는 사건의 결과 를 파국적으로 생각하는 경향이다. 예컨대 "나는 시험을 못 보 는 편이고, 어제도 못 봤다. 그래서 학교는 괴로운 장소이고 시 간낭비를 하고 있다.”라는 류의 생각이다(Bae, 2014). 재앙화 에 담긴 극단적 사고 경향은 이분법적 사고와 유사하다. 따라 서 초등학생의 경우도 이분법적 사고에 의지하면, 작은 실수 나 실패를 재앙화하여 자신을 패배자로 지각할 수 있다.

학령기 아동의 분노 조절을 위한 인지행동프로그램(Jeong, 2010)에서도 파국적 재앙화나 이분법적 사고와 같은 극단적 인 부적응적 인지과정이 분노를 유발하는 결정적 요인이었으 며, 이러한 왜곡된 사고를 수정함으로써 분노를 조절할 수 있 었다. 또한 초기 청소년을 대상으로 한 연구에서는 이분법적 사고가 무망감, 우울, 자살 사고 등과 정적 상관을 보였는데 (Yun, 2014), 이는 성인 연구에서 이분법적 사고가 우울증, 자 살과도 연관되어 있다는 발견과 일치한다(Litinsky \& Haslam,
1998). 따라서 아동기에서도 이분법적 사고는 부정적 사건의 재앙화, 자신에 대한 부정적 개념화, 분노 조절 곤란 등의 부적 응과 병리에 영향을 주는 인지적 취약성일 수 있다.

이분법적 사고를 가지고 있는 아동 및 청소년은 주변 환경 에서 받아들이는 정보를 이분화하여 극단적으로 해석한다. 양 극화된 해석은 강한 정서를 유발하고, 이는 다시금 후속되는 정보의 처리를 왜곡하는 굴레를 형성한다. 그러므로 이분법적 프레임으로 사고하는 사람들에게는 순기능적 측면보다 역기 능적 측면이 더 많다(J. Y. Lee, 2014). 초등학생이 극단적인 프 레임으로 세상을 바라보면 우울이나 분노와 같은 부정적 정서 가 강화되고, 수행 능력이 저하되며, 자살과 같은 극단적 행동 이 이어질 수 있다. 인지적 취약성 요인임에도 불구하고 초등 학생의 이분법적 사고를 주요 변인으로 탐색한 연구는 없었다. 이를 위해서는 먼저 이분법적 사고를 측정하는 도구의 개발이 선행되어야 한다(S. J. Joe \& Doh, 2018). 본 연구에서는 아동의 이분법적 사고를 연구하기 위한 출발점으로서 이를 측정하는 자기보고 척도를 개발하고자 한다.

성인의 이분법적 사고를 평가하기 위한 척도들이 다양하게 개발된 바 있다. Byrne, Cooper와 Fairburn (2004)의 이분법적 사고 척도(Dichotomous Thinking Scale [DTS])가 최초의 자기 보고식 검사이다(Ko \& Hwang, 2012). 또한 건설적 사고 척도 (Constructive Thinking Inventory [CTI]; Epstein \& Meier, 1989) 에 속한 범주적 사고 하위척도(categorical thinking subscale)와 역기능적 태도(Dysfunctional Attitude Scale [DAS])에 속한 이 분법적 사고 하위척도(Dyck, 1992)등이 개발되었다(Hwang, 2009). 그러나 DTS, DAS의 이분법적 사고 하위척도, CTI의 범주적 사고 하위척도 등은 모두 섭식 문제에서 드러나는 이 분법적 사고를 측정하기 위한 것이므로 범용성이 제한된다. 이와 다르게, 특정 정신병리 맥락에 국한되지 않은 이분법적 사고의 작용을 탐색하기 위한 척도로는 개정판 이분법적 사 고 지표(Dichotomous Thinking Index-30 Revised [DTI-30R]; Hwang, 2007)를 들 수 있다.

DTI-30R은 총 6개의 하위요인을 통해 이분법적 사고를 측 정한다. 첫 번째 요인은 '이것 아니면 저것'과 같이 중간지대 가 없이 양극단의 선택만이 있는 '양단결정'이고, 두 번째 요 인은 '모 아니면 도', '잘한 것이 아니면 곧 못한 것'과 같은 '전 부 대 전무의 사고'이다. 세 번째 요인은 '완전한 성공이 아니 면 완전한 실패'와 같은 '성공 대 실패의 이분법'이며 네 번째 요인은 대인관계의 영역에서 중간지대를 인정하지 않고 '내 편 대 네 편'으로 나누는 '편 가르기'이다. 다섯 번째 요인은 '지각하느니 차라리 결석하는 편이 낫다'와 같이 지각이나 시 
험에 관한 이분법적 사고인 ‘학업상의 이분법’이고, 여섯 번째 요인은 언어사용에 있어 최상급 표현과 단정적인 표현을 자 주 사용하는 '어법상의 이분법'이다. 본 연구에서는 특정 정신 병리 맥락에 국한되지 않고 성인의 이분법적 사고를 측정하 는 DTI-30R을 모태로 하여, 아동의 인지적 발달 수준에 적합 한 이분법적 사고 척도를 개발하여 타당화하고자 하였다.

이분법적 사고는 아동의 인지 발달 단계 중 전조작기와 유 사한 특징을 보인다. 전조작기의 아동은 사물을 판단할 때 단 계적으로 배열하는 것이 어렵고, 확장된 사고를 동원해서 연 속선상에서 고려하는 것이 힘들기 때문에 ‘좋고', ‘나쁨'의 이분법적 사고의 판단 양식이 자연스럽게 등장한다. Piaget (1952)에 따르면, 판단을 연속적인 차원에 따라 내릴 수 없으 므로, 전조작기의 아이들은 친구를 분류할 때도 '완전 똑똑이 (all smart)' 아니면 '멍청이(all dumb)'같은 양분법을 사용한다 (Hwang, 2007; Ko \& Hwang, 2012). 아동의 도덕성 발달 이론 에 따르면 전조작기에 해당하는 아동들은 규칙에 무조건적으 로 복종하고, 옳고 그름의 절대적인 양극적 사고를 하며, 밖으 로 나타난 행동의 결과만 중시하고 내면의 동기나 의도를 고 려하지 못한다(Ginsburg \& Opper, 1988/2006).

하지만 구체적 조작기에 들어서면 스스로 규칙을 만들고, 규칙의 변경을 받아들이며, 민주 시민으로서의 준법성을 갖 게 된다. 동시에 구체적 조작기의 아동은 추상적 개념을 이해 하고, 구체적 사물을 중심으로 이론적 사고가 발달하기 시작 하며, 의도성, 상대성, 잘못에 대한 기준, 상호성, 배상과 교정 으로서의 처벌, 인과관계에 대한 이해를 획득한다(Ginsburg \& Opper, 1988/2006). 이러한 과정을 통해 구체적 조작기의 아동 은 이분법적 사고의 영향에서 점차 벗어나게 된다.

초등학교 고학년 시기에 해당되는 형식적 조작기에 이르면 아동은 추상적 개념을 이해하고 가설의 설정 및 검증과 함께 연역적 사고를 할 수 있다. 이 시기 아동들은 대상들을 유목으 로 묶어 나눌 수 있게 된다. 이 과정에서 조합적 체계가 나타나 서 사고력을 확장시키고, 대상과 대상을, 그리고 명제와 명제 를 결합할 수 있게 된다(Ginsburg \& Opper, 1988/2006). 유목 화가 불가능한 전조작기와 비교하여, 사고를 결합하고 연속선 상에서 판단할 수 있으므로, 형식적 조작기의 아동들은 다양 한 선택지에 따른 판단 즉, 다분화된 사고가 가능해진다. 따라 서 전조작기를 벗어나 구체적 혹은 형식적 조작기에 이른 아 동이 이분법적 사고를 지속적으로 보인다면, 이는 인지발달에 비추어 일탈적인 현상으로서 인지적 개입의 대상이 될 수 있 다. 본 연구에서는 형식적 조작기나 적어도 구체적 조작기에 있을 것으로 가정되는 초등학교 4-6학년생을 대상으로 이분
법적 사고를 측정하고자 한다.

초등학교 4-6학년생들에게 이분법적 사고가 인지발달에 비해 미숙하고 부적응적인 판단 양식이라면, 이 아동들을 대 상으로 인지적 개입을 통해 사고 방식을 변화시키는 것이 가 능한지도 함께 검토될 필요가 있다. Verduyn (2000)에 따르 면 초등학교 3-4학년생의 인지적 발달 수준은 구체적 조작기 에 해당하는데, 이 아동들은 인지행동치료(Cognitive Behavior Therapy [CBT])를 이해하고 과제를 수행할 수 있다. 이 시기의 아동은 은유, 상징, 비유 등을 통한 설명을 이해하고, 인지적 재구성에 필요한 인과관계에 대한 이해와 논리적 추론을 할 수 있다. 국내에서도 초등학교 4-6학년 아동들을 대상으로 비 합리적 신념에 대한 인지적 재구성 프로그램의 실행 가능성 이 확인되었다(Y. K. Lee, 2015). 따라서 초등학교 4-6학년생을 대상으로 왜곡된 판단 양식을 인지행동적 접근으로 재구성하 는 것은 실행가능성(feasibility)이 있으므로, 본 연구에서는 이 연령층의 아동들을 대상으로 그들의 인지발달에 비춰 미숙하 고 병리적인 판단양식인 이분법적 사고를 평가하는 척도를 먼저 개발하여, 향후 이를 교정하는 인지행동프로그램의 선 행단계를 준비하고자 한다.

성인 연구에서 이분법적 사고는 여러 병리에 걸쳐 범진단 적 인지적 취약성으로 작용하므로, 아동용 이분법적 사고 지 표가 개발된다면 성인에서 이뤄진 다양한 연구에 대응하는 아동판 연구가 향후에 시도될 수 있을 것이다. 그러나 아동의 이분법적 사고가 범진단적 인지적 취약성으로 작용한다는 것 을 보일 수 있는 최소한의 초기 연구가 필요하다. 이를 위해서 본 연구에서는 대표적인 부정 정서인 우울과 불안, 그 기저 요 인으로 작용할 수 있는 자존감과 이분법적 사고의 관계를 알 아보고자 했다.

성인 연구에서 이분법적 사고는 우울과 불안 각각을 증가 시키며(Beck et al., 1976; Hwang, 2009; Hwang \& Lee, 2012), 불투명한 자기 개념 명료성과 낮은 자존감과 관련되어 있 었다(Hwang, 2009). 또한 초기 청소년을 대상으로 한 연구 에서 이분법적 사고는 자살사고, 무망감 우울 등과 정적 관 계를 보였고(Yun, 2014), 이분법적 사고를 가진 아동, 청소년 은 우울, 불안 등의 정서적 영역에서 문제를 보였다(BenowitzFredericks, Garcia, Massey, Vasagar, \& Borzekowski, 2012; Hammond \& Romney, 1995; Park, 2017). 따라서 아동에서도 이분법적 사 고가 다양한 병리에 작용하는 인지적 취약성이라면, 우울 및 불안과는 정적 상관을, 자존감과는 부적 상관을 보일 것이라 가정할 수 있는데, 본 연구에서는 이 가정을 아동용 이분법적 사고 지표의 준거 관련 타당도로 검증하고자 한다. 
요약하면, 본 연구는 성인의 이분법적 사고 지표를 모태로 하여, 초등학교 4-6학년 아동들에게 부적응적으로 작용할 수 있는 이분법적 사고를 측정하는 자기 보고 척도를 개발하고 자 한다. 이 시기의 아동의 발달단계에 부합하는 척도를 개발 하고, 탐색적 요인 분석을 통해 구성 타당도를 확인하고, 이어 서 탐색된 요인 구조를 별개의 표집에서 확인적 요인분석을 통해 교차 타당화하고자 한다. 이어서, 아동용 이분법적 사고 지표의 내적 일관성 신뢰도와 검사-재검사 신뢰도를 산출하 고, 우울, 불안, 낮은 자존감 등을 준거로 공존 타당도를 확인 고자 한다.

\section{연구문제 1}

아동용 이분법적 사고지표(Dichotomous Thinking Index for Children [DTI-C])는 아동의 이분법적 사고를 타당하고 신뢰 롭게 측정하는가?

\section{1-1. 아동용 이분법적 사고지표를 구성하는 요인은 무엇인 가?}

1-2. 아동용 이분법적 사고지표의 타당도와 신뢰도 수준은 적절한가?

\section{Methods}

\section{연구대상}

경기도에 소재한 초등학교에서 가, 나, 다 급지별로 학교를 임 의 선정하여 4-6학년 학생을 대상으로 설문을 실시하였다. 예 비문항작성을 위해 4-6학년 32명을 대상으로 설문을 실시하 였고, 예비 조사의 문항 이해도 평가를 위해 4-6학년 120명을 대상으로 설문을 실시하였다. 본 조사의 문항 개발 및 요인분 석을 위해 총 300 부의 설문지를 배부하여 회수된 289부의 설 문지 중, 무성의하게 응답된 18 부를 제외한 271 부를 대상으로 탐색적 요인분석을 실시하였다. 이어서 교차 타당화를 위한 확인적 요인분석을 위해 새롭게 선정된 학교에 210 부의 설문 지를 배부하여 회수한 설문지 중, 무성의하게 응답한 10 부를 제외한 200 부를 대상으로 확인적 요인분석과 신뢰도 및 타당 도 검증을 하였다. 추가적으로 검사-재검사 신뢰도를 위해 5-6 학년 학생 70 명을 대상으로 설문을 실시하였다.

예비문항 작성을 위한 연구표집(구분을 위해 표집 A라고
함)의 사회 인구학적 특성을 살펴보면, 성별은 남학생이 17 명으로 $53.1 \%$, 여학생이 15 명으로 $46.9 \%$ 이었다. 4학년이 12 명으로 $37.6 \%, 5$ 학년이 10 명으로 $31.2 \%, 6$ 학년이 10 명으로 $31.2 \%$ 이었다. 예비조사의 문항 이해도 평가를 위한 연구표집 (구분을 위해 표집 B라고 함)은 남학생이 60명으로 50\%, 여학 생이 60으로 $50 \%$ 이었고, 4학년이 42 명으로 $35 \%, 5$ 학년이 58 명으로 $48.3 \%, 6$ 학년이 20 명으로 $16.7 \%$ 이었다.

본 조사의 척도 개발을 위한 연구표집(구분을 위해 표집 C 라고 함)은 남학생이 143 명으로 $52.8 \%$, 여학생이 128 명으로 $47.2 \%$ 이었다. 4 학년이 69명으로 $25.5 \%$, 5학년이 130 명으로 $48 \%, 6$ 학년이 72 명으로 $26.6 \%$ 이었다. 확인적 요인분석 및 내 적 일관성 신뢰도를 위한 연구표집(구분을 위해 표집 $\mathrm{D}$ 라고 함)은 남학생은 112 명으로 $56 \%$, 여학생은 88 명으로 $44 \%$ 이었 고, 4학년이 38 명으로 $19 \%$, 5학년이 50 명으로 $25 \%, 6$ 학년이 82 명으로 $41 \%$ 이었다. 검사-재검사 신뢰도를 알아보기 위한 연구표집(구분을 위해 표집 $\mathrm{E}$ 라고 함)은 남학생이 35명으로 $50 \%$, 여학생이 35 명으로 $50 \%$ 이었고, 5 학년이 22 명으로 $31 \%$, 6학년이 48 명으로 $69 \%$ 이었다.

\section{연구도구}

본 연구에서는 아동용 이분법적 사고 지표를 개발한 후 그 타 당도를 검증하는 단계에서 세 가지 척도를 활용하였다. 타당 도 검증을 위해 활용한 척도는 아동용 우울척도, 아동 특성 불 안 척도, 로젠버그 자존감 척도이다. 아동용 우울척도에서 응 답 점수가 높을수록, 아동 특성 불안 척도에서 응답점수가 높 을수록 높은 우울과 불안을 반영하며, 자존감 척도의 점수가 높을수록 높은 자존감을 반영한다.

\section{아동용 우울 척도}

(Kovacs's Children's Depression Inventory [CDI])

Beck의 우울 척도를 8-17세 아동 및 청소년의 인지, 정서, 행동 적 우울 증상들을 평가하기 위해 제작된 자기보고식 검사인 CDI (Kovacs, 1983)를 Cho와 Lee (1990)가 번안하여 타당화한 한국형 소아 우울 척도를 사용하였다. 27 개 문항으로 구성되 어 있으며 지난 2주일동안의 자신의 기분 상태를 스스로 평가 한다. 3 개의 서술문을 0 점, 1 점, 2 점으로 하여 채점한다. 본 연 구의 표집 D에서 Cronbach's $\alpha$ 는 .923으로 나타났다. 
아동 특성불안 척도

(Trait Anxiety Inventory for Children [TAIC])

20개 문항으로 구성된 아동 특성 불안 검사(TAIC; Spielberger, 1973)를 S. Joe와 Choi (1989)가 번안하여 초등학생을 대상으 로 표준화한 척도를 사용하였다. 특성불안은 불안을 일으키 는 경향으로 개인이 지니고 있는 지속적인 특성을 의미하는 데, 자기보고식으로 불안을 평소에 어떻게 느끼고 있는가를 표시한다. 3점 Likert 척도로 되어 있고 점수가 높을수록 평 소에 느끼는 불안이 높다고 평가한다. 본 연구의 표집 $\mathrm{D}$ 에서 Cronbach's $\alpha$ 는 .920로 나타났다.

\section{로젠버그 자존감 척도}

(Rosenberg Self-Esteem Scale [RSES])

자존감 척도는 RSES (Rosenberg, 1965)를 H.-J. Lee와 Won (1995)이 번안하여 S. Y. Lee (2007)가 수정한 검사를 사용하 였다. 이 도구는 총 10 문항에 대해 본래 5 점 척도로 응답하게 되어있으나, 아동을 대상으로 한 본 연구에서는 아동의 문항 이해도를 고려하여 4점으로 변형하여 사용하였다. 부정적 문항은 역 채점문항으로 구성되어 있으며 점수가 높을수록 자존감이 높은 것을 의미한다. RSES는 본래 청소년 및 성인 을 대상으로 자존감을 측정하는 척도이지만 문항의 개수가 많지 않고, 문항내용이 어렵지 않아서 초등학생을 대상으로 한 연구에서도 활용되고 있다(Yoon \& Ryu, 2007). 본 연구의 표집 $\mathrm{D}$ 에서 Cronbach's $\alpha$ 는 .768로 나타났다.

\section{연구절차}

아동용 이분법적 사고지표 개발 및 타당화 연구를 위해 예비 문항작성-예비조사-본조사의 단계로 척도 제작이 이루어졌 고, 3 단계 절차는 다음과 같이 진행되었다.

예비문항작성에서 성인용 이분법적 사고 지표인 DTI-30R 의 6개 하위요인을 아동용 이분법적 사고척도의 하위요인으 로 구성하였고, 4-6학년 아동을 대상으로 한 예비설문과 담임 교사들을 대상으로 아동의 이분법적 사고에 관한 협의를 거쳐 문항들을 선정하였다. 또한 초등학생의 이분법적 사고와 관련 된 문항을 수집하기 위하여 4-6학년 초등학생 32명(표집 A)을 대상으로 설문조사를 실시하였다. 이분법적 사고에 대한 정의 를 학생들에게 설명하고 아동들이 경험해 본 이분법적 사고의 예를 자유롭게 작성하도록 하였다. 수집된 내용 중 공통된 경
험이나 에피소드를 문항화했고, 이에 DTI-30R의 성인문항들 을 아동의 수준에 적합하게 바꾼 것을 첨가하여 1 차 예비문항 을 작성하였다.

예비조사에서는 척도 구성의 적절성, 내용의 이해도 평정 및 실시방법과 소요시간 등을 점검하였다. 1 차 예비문항을 연 구자와 임상심리전문가 1 인, 교육상담 석사 이상의 학위를 소 지한 초등학교 교사 10 명이 점검하였다. 교사 10 인에게 이분 법적 사고의 개념을 소개하고, 성인용 이분법적 사고 지표와 선행 연구들을 교육하였다. 교사들은 이 과정을 통해 이분법 적 사고의 정의와 구성요소를 이해한 후 예비 문항의 적절성 을 검토하였다. "문항들이 이분법적 사고의 정의와 하위요인 에 얼마나 일치하는가?”, “검사지 형태가 적절한가?”, “질문이 얼마나 명료한가?”, “중복된 질문은 없는가?”의 기준에 따라 문항을 검토하였고, 1 인의 임상심리전문가와 함께 총괄적으 로 문항내용을 평정하였다. 이어 초등학교 4-6학년 학생 120 명(표집 B)을 대상으로 예비 문항에 대한 이해정도를 이해하 기 쉽다, 보통이다, 이해하기 어렵다의 세 단계로 평가하도록 하였다. 아이들이 이해하기 어렵다고 응답한 문항은 적절한 언어로 바꾸어 수정하였다. 검증 과정을 통해 선정된 20 문항 을 임상심리전문가 1 인과 함께 검토하여 최종 설문지가 작성 되었다. 최종설문지는 18 개 문항으로 5점 Likert척도이다.

본 조사는 먼저 각 학교에 연구의 목적을 알리고 협조를 구 한 뒤 각 급지별로 골고루 선정된 초등학교의 4, 5, 6학년(표집 $\mathrm{C}, \mathrm{D}, \mathrm{E})$ 을 대상으로 설문을 실시하였다. 아동용 이분법적 사 고 지표 개발 단계를 도식화하면 다음과 같다(Figure 1).

\section{자료분석}

수집된 자료의 분석을 위해, SPSS 21.0 (IBM Co., Armonk, $\mathrm{NY}$ )과 AMOS 21.0 (IBM Co., Armonk, NY)을 활용하였다. 이 분법적 사고의 요인구조를 알아보기 위해 표집 $\mathrm{C}$ 에서 탐색 적 요인분석을 실시하였는데, 추출은 주성분 분석 방식을, 회전은 카이저 정상화에 의한 베리맥스 회전방식을 적용하 였다. 다음으로, 탐색된 요인구조를 바탕으로 별도의 표집 D 에서 확인적 요인분석을 실시하였다. 모형 적합도 지수로는 TLI, CFI, RMSEA를 사용하였다. 준거 관련 타당도의 검증 을 위해 표집 $\mathrm{D}$ 에서 우울, 불안, 자존감과의 상관 분석을 실 시하였다. 신뢰도 검증을 위해 Cronbach's $\alpha$ 계수를 산출하였 으며, 표집 $\mathrm{E}$ 를 대상으로 4 주 간격의 검사 재검사 신뢰도를 측정하였다. 


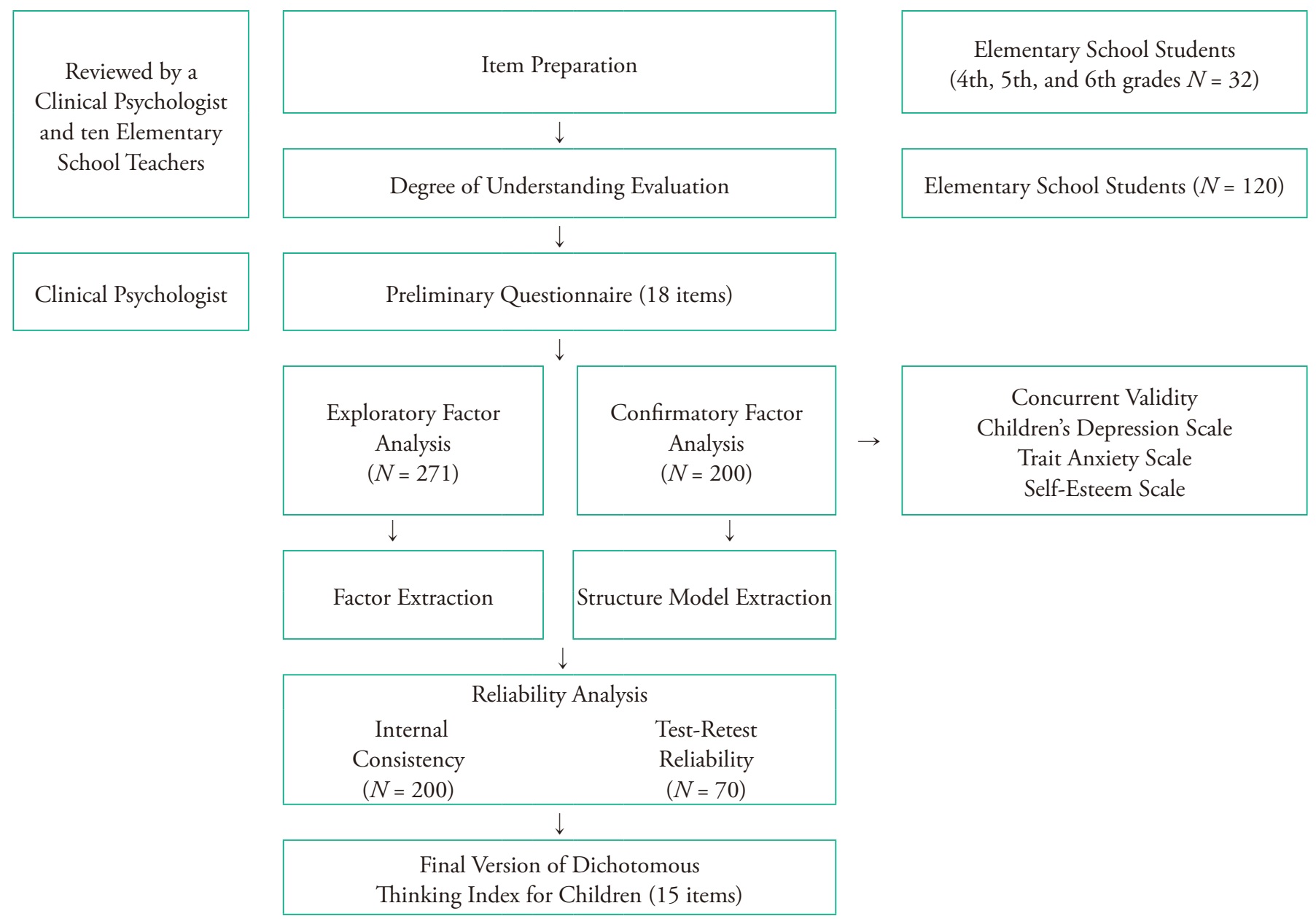

Figure 1. Procedure of developing and validating the DTI-C.

\section{Results}

\section{아동용 이분법적 사고 지표의 구성 및 양호도}

\section{탐색적 요인분석}

탐색적 요인분석의 사전단계로 수집된 자료가 요인분석에 적합한지 점검하였다. 그 결과, $\mathrm{KMO}$ 표집 적합성 측도(kaiser-meyer-olkin measure of sampling adequacy)는 .865이었고, Bartlett의 구형성 가정도 기각되어서 $\chi^{2}=1303.638, p<.001$, 요인분석이 가능한 것으로 나타났다(Seo, Lee, Kim, \& Kim, 2018). 요인분석을 실시하기 위한 사례수는 문항수의 적어도 4-5배는 되어야 하는데(Seong, 2002) 본 연구표집(표집 C)은 271 명으로 18 문항척도의 요인분석을 위한 충분한 사례수를 포함하였다. 요인추출방법으로 주성분분석을, 회전방법으로 는 베리맥스를 사용하였다.
탐색적 요인분석 결과, 스크리 도표(scree-test)에서 4요인 이 존재하는 것으로 나타났다. 문항의 이론적 토대가 되었던 DTI-30R (Hwang, 2007)의 6요인 구조와는 달리 아동용 이분 법적 사고지표에서는 4 요인 구조가 나타났다. 요인부하량의 절대값이 .50 이상이었지만 문항이 해당되는 요인에 적절하게 묶이지 않고, 측정항목이 해당요인을 설명하지 못하는 3 문항 을 삭제하여 최종 15 개 문항을 선정하였다.

각 요인들을 살펴보면 요인 1 은 선택지가 양극단의 범주만 이 있는 이분법에 대한 내용을 포함하고 있다. 선택의 중간지 대가 존재하지 않는 극단적인 결정이 주를 이루어 '양단결정' 이라 명명하였다. 요인 2는 수행에 있어 완벽한 성공이 아니 면 작은 실수를 했을 때에도 극단적으로 실패했음과 동일하 게 여기는 이분법에 대한 내용을 포함하고 있어 '성공과 실패 의 이분법'이라고 명명하였다. 요인 3은 대인관계에서 “내 편 이 아니면 적이다.”와 같은 이분법적 사고가 드러나 “편 가르 기'로 명명하였다. 요인 4는 ‘최고' 또는 ‘최상' 등과 같은 극단 
Table 1

Exploratory Factor Analysis of DTI-C

\section{Factor}

\begin{tabular}{llllll}
\cline { 2 - 4 } Item & 1 & 2 & 3 & 4
\end{tabular}

15. In the world, there are only two kinds of individuals: one is good, and the other is bad.

5. Everything that happens to me tends to be either really good or very terrible.

\begin{tabular}{|c|c|c|c|}
\hline .692 & .091 & .035 & -.103 \\
\hline .675 & .149 & .115 & .225 \\
\hline .642 & .188 & .066 & .076 \\
\hline .607 & .115 & .204 & .050 \\
\hline .594 & .434 & .021 & .081 \\
\hline .583 & .487 & -.031 & .188 \\
\hline .426 & .172 & .205 & .051 \\
\hline .090 & .736 & -.003 & .081 \\
\hline .167 & .644 & .152 & .215 \\
\hline .388 & .633 & .131 & .048 \\
\hline .427 & .566 & .135 & .015 \\
\hline .151 & .560 & .421 & -.001 \\
\hline .102 & .083 & .834 & .013 \\
\hline .082 & .276 & .698 & .074 \\
\hline .421 & -.115 & .540 & .242 \\
\hline .152 & -.079 & .022 & .760 \\
\hline-.075 & .177 & .007 & .742 \\
\hline .141 & .208 & .161 & .490 \\
\hline 4.89 & 1.31 & 1.24 & 1.16 \\
\hline 32.51 & 8.75 & 8.31 & 7.74 \\
\hline 32.51 & 41.56 & 49.57 & 57.31 \\
\hline
\end{tabular}

13. When taking a test that I haven't studied for, I'd rather leave the exam blank than risk getting a poor score.

9. There is only one correct answer to an examination question.

18. I always feel good or terrible.

8. If something is not done perfectly, it means that it is not done well.

7. I have no interest in friends that I am not close to.

6. I feel good, only when I get 100 points.

17. I feel unhappy when my work is not perfect.

11. When I make a small mistake, I feel terrible.

16. If I were to make a mistake in the school play, I would feel extremely terrible.

12. If I make a mistake when drawing, I want to start over on a new piece of paper.

1. I am clear in the distinction between friends I like and those I dislike.

10. I am clear in the distinction between the things that I like versus what I dislike.

4. Classmates are divided into two groups: close or not close to me.

2. I tend to use the words 'certainly,' 'exactly,' and, 'completely' when talking with friends.

14. I tend to use decisive expressions such as 'best,' 'very,' and 'the most' when describing people or situations.

3. I prefer a subject that has a definite answer over a subject that has an unclear answer.

$\begin{array}{ccccc}\text { Eigenvalue } & 4.89 & 1.31 & 1.24 & 1.16 \\ \text { \% of variance } & 32.51 & 8.75 & 8.31 & 7.74 \\ \text { Cumulative \% } & 32.51 & 41.56 & 49.57 & 57.31\end{array}$

Note. $N=271$.

Three items $(3,7$, and 10$)$ were deleted because they did not show proper factors.

적인 언어를 자주 사용하여 '어휘상의 이분법’으로 명명하였 다. 네 개 요인은 전체변량의 $57.31 \%$ 을 설명하였다(Table 1 ).

\section{확인적 요인분석}

탐색적 요인분석에서 밝혀진 최종 15 개 문항의 4 개 요인구조 의 안정성을 확인하기 위해 초등학교 4-6학년 학생 200명을
새롭게 표집(표집 D)하였다. 200명을 대상으로 확인적 요인 분석을 실시하여 요인구조의 일반화 가능성을 탐색하였다.

모형의 적합도를 검증하기 위하여 CFI, TLI, RMSEA를 선 택하였다. CFI는 모형의 간명성은 고려하지 않지만 표본의 크 기로부터 영향을 받지 않으면서 모형오류를 측정할 수 있고, TLI와 RMSEA는 표본크기에 민감하게 영향을 받지 않으면서 도 모형의 간명성도 고려하는 지표이다. RMSEA의 경우 .05미 
Table 2

Fit Index of the 4-Factor Structure of the DTI-C

\begin{tabular}{ccccc}
\hline CMIN & CMIN/DF & RMSEA & TLI & CFI \\
\hline 136.666 & 1.627 & .056 & .907 & .926 \\
\hline
\end{tabular}

Note. $N=200$.

만이면 좋은 적합도, .08미만이면 괜찮은 적합도, .10보다 크 면 나쁜 적합도로 간주되며, CFI와 TLI는 .90이상이면 모형의 적합도가 좋은 것으로 본다(Hong, 2000).

본 연구에서는 전체 15 문항이 4 요인(양단결정, 성공과 실 패의 이분법, 편 가르기, 어휘상의 이분법)에 지정되어 부하되 는 모형에 대한 적합도 기준을 도출하였다. 그 결과 CFI값은 0.926 , TLI값은 0.907, RMSEA값은 0.056로 양호한 적합도를 나타내 4 개 요인 구조가 이분법적 사고를 측정하기에 적합함 을 확인하였다(Table 2).

모형의 타당성을 평가하기 위해 4 개 요인을 가정한 연구 모 델에서 각 요인의 요인 부하량과 표준화 요인 부하량을 살펴 보았다(Figure 2). 구조방정식 모형에서 산출된 검사의 잠재변 수와 측정변수의 요인 부하량과 표준화 요인 부하량은 모두 통계적으로 유의하므로 확인적 요인분석의 결과에서 나타난 4 개 하위요인을 그대로 수용하였다. 더 나아가 측정항목이 구 성개념을 일관성 있게 측정하였다면 항목들 간의 높은 상관 이 있을 것이고, 잠재변수에서 관측변수로 가는 요인부하량은 .50 이상을 보일 것으로 가정한다. 본 연구 모형에서 잠재변수 에서 관측변수로 가는 표준화된 요인부하량(standardized factor loading)이 .50 이상으로 측정항목들이 구성개념을 타당하게 측 정하고 있다는 점을 확인하였다.

\section{아동용 이분법적 사고 지표의 타당도 및 신뢰도}

\section{준거관련 타당도}

아동용 이분법적 사고 지표의 타당도 분석을 위해 이분법적 사고와 유사한 구성개념을 측정하는 척도의 상관계수를 살펴 보았다. 본 연구에서는 아동용 우울척도(CDI), 아동용 특성불 안척도(TAIC), 로젠버그 자존감척도(RSES)를 준거변인으로 선정하였다. 아동용 이분법적 사고지표와 제시된 아동척도들 과의 상관관계는 모두 유의하였다(Table 3). 이분법적 사고는 우울 척도와 $r=.562, p<.01$ 로 유의한 정적상관이 있는 것으 로 나타났으며, 불안척도와도 $r=.732, p<.01$ 로 유의한 정적 상관이 있는 것으로 나타나 이분법적 사고의 점수가 높은 아

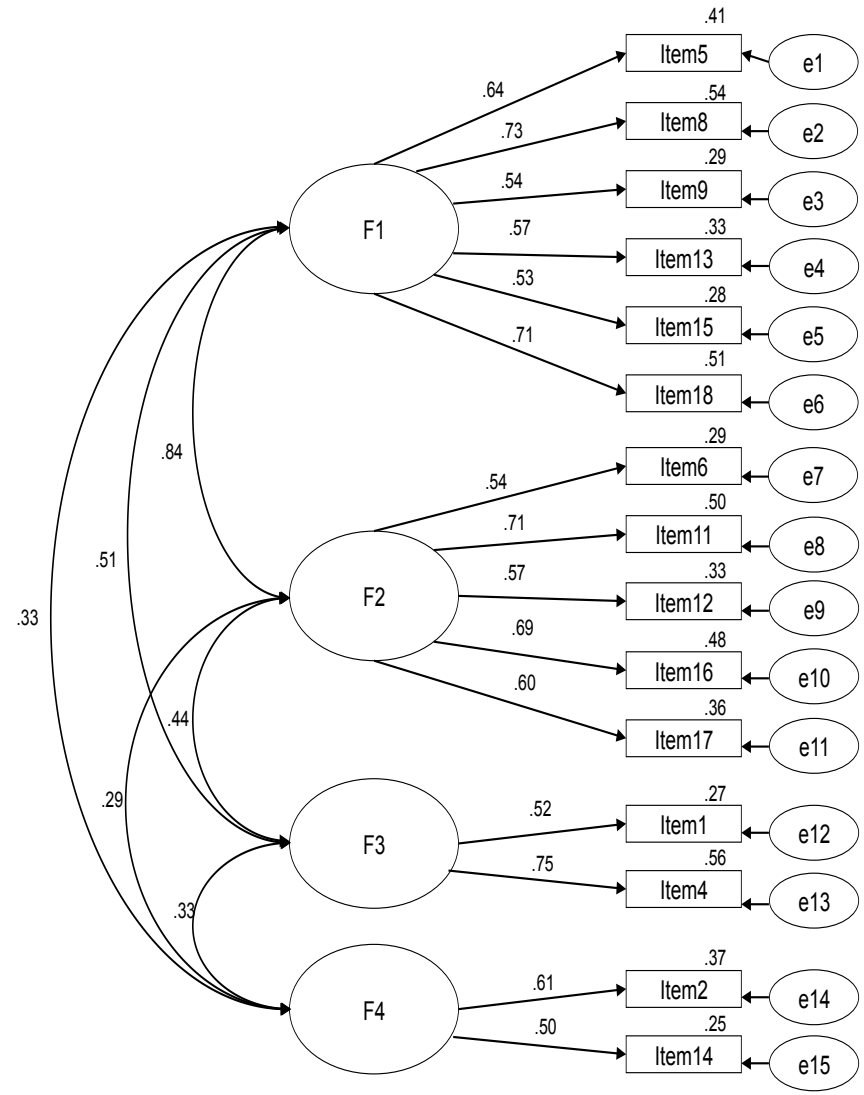

Figure 2. Factor loading. F1 = extreme decision; F2 = success or failure; F3 = social splitting; F4 = dichotomous thinking in verbalization.

Table 3

Correlation of Scale Values Between the DTI-C and Major Psychopathology

\begin{tabular}{cccc}
\hline & DTI-C & CDI & TAIC \\
\hline CDI & $.562^{* *}$ & & \\
TAIC & $.732^{* *}$ & $.803^{* *}$ & \\
RSES & $-.427^{* *}$ & $-.744^{* *}$ & $-.672^{* *}$ \\
\hline
\end{tabular}

Note. $N=200$.

${ }^{* *} p<.01$.

동이 우울 및 불안 척도의 점수도 높다는 것을 알 수 있다. 또 한 이분법적 사고는 자존감 척도와 $r=-.427, p<.01$ 로 유의한 부적상관이 있는 것으로 나타나 이분법적 사고가 높을수록 자 존감은 낮아지는 양상을 확인할 수 있다.

마지막으로 아동용 이분법적 사고 지표의 신뢰도를 검증하 기 위해 Cronbach's $\alpha$ 계수를 산출하였다. 전체 Cronbach's $\alpha$ 계수는 .85 이었으며, 각 요인별로는 양단결정이 .79, 성공과 실패의 이분법이 .76 , 편가르기가 .53 , 어휘상의 이분법이 .46 
Table 4

Cronbach's a of DTI-C

\begin{tabular}{lccc}
\hline & Factors & Items & Cronbach's $\alpha$ \\
\hline Extreme decision & 6 & .79 \\
Success or failure & 5 & .76 \\
Social splitting & 2 & .53 \\
Dichotomous thinking in verbalization & 2 & .46 \\
\hline Total & 15 & .85 \\
\hline
\end{tabular}

Note. $N=200$.

으로 나타났다(Table 4).

추가적인 신뢰도 분석을 위해 초등학교 5-6학년 학생 70명 을 대상(표집 E)으로 검사-재검사 신뢰도를 측정하였다. SPSS 를 통해 4주 간격의 결과 값을 상관계수로 검증하였다. 4 주 간 격의 검사-재검사 신뢰도는 .87로 나타났다.

\section{Discussion}

본 연구의 목적은 초등학생의 이분법적 사고를 측정하기 위한 척도를 개발하는 것이다. 개발된 아동용 이분법적 사고 지표 의 구성개념 타당도(construct validity)는 탐색 및 확인적 요인 분석을 통해, 그리고 우울, 불안 및 자존감과의 예측된 상관패 턴을 통해 검증되었다. 본 연구결과를 요약하고 논의하면 다 음과 같다.

첫째, 아동용 이분법적 사고 지표는 '양단결정', '성공 대 실 패', '편가르기', ‘어휘상의 이분법'의 네 가지 요인으로 구성되 었다. 이분법적 사고의 이론에 현직 교사들의 관찰을 더해 얻 은 자료를 바탕으로 문항을 제작하였는데, 4 요인 총 15 개의 척도가 만들어졌다. 이론적 토대가 된 Hwang (2007)의 DTI$30 \mathrm{R}$ 의 하위요인 6 개와 비교하였을 때 2 개 요인이 줄어든 4 개 의 요인이 추출되었다. 이러한 결과는 학령기 아동들의 이분 법적 사고가 성인과 비교하였을 때, 영역별로 분리되기 보다 는 통합적으로 나타나고 있음을 나타낸다. 요인의 내용적 폭 이 감소한 것은 이분법적 사고가 발현되는 환경이 학교로 한 정되어 축소되었기 때문일 수 있다.

또한 그 세부적인 구성의 차이를 살펴볼 필요가 있는데, 연 구 대상인 $4,5,6$ 학년인 초등학교 학령기 아동들은 발달 시기 상 근면성과 학업의 성취에 발달과업을 두고 있다(Ginsburg \& Opper, 1988/2006). 이를 뒷받침하는 근거로 다른 요인에 비해 많은 수의 문항들이 각각 양단결정(6문항)과 성공과 실패의 이분법(5문항) 요인에 묶여있다. 연구대상의 이분법적 사고가
주로 학업 및 학교생활의 성취에 대한 성공과 실패에서 드러 나고 있음을 나타낸다.

둘째, 새로운 표집을 대상으로 척도의 적합성을 검증하였 다. 확인적 요인분석을 실시한 결과, TLI, CFI, RMSEA가 모두 기준을 만족하여 적합도가 좋은 모형임을 나타냈고, 4 요인 구 조는 일반화 될 수 있는 모형임이 확인되었다. 편 가르기와 어 휘상의 이분법에서는 요인별 문항의 개수가 각각 2 개로 상 대적으로 적은 문항을 가지고 있어 측정에 다소 낮은 신뢰도 를 나타냈지만, 전체 척도의 내적 합치도와 4 주 간격의 검사재검사 신뢰도는 양호했다.

셋째, 선행연구에서 이분법적 사고가 설명하는 병리 변인 을 통해 아동용 이분법적 사고척도의 타당도를 검증하였다. 아동용 이분법적 사고 지표(DTI-C)는 성인용 이분법 척도와 정신병리의 관계로부터 예측되듯이 아동 우울척도(CDI) 및 아동 특성 불안척도(TAIC)와는 유의한 정적 상관을 자존감 척도(RSES)와는 유의한 부적 상관을 보여서, 정신병리에 비 춘 준거관련 타당도는 지지되었다. 이는 이분법적 사고를 가 진 아동, 청소년은 우울, 불안 등의 정서적 영역에서 문제를 보 인다는 선행연구(Benowitz-Fredericks et al., 2012; Hammond \& Romney, 1995; Park, 2017)와도 일치한다. 또한 아동의 이분법 적 사고가 우울, 불안 등의 정신 병리와 유의미한 상관을 나타 내고 있음을 확인하여, 발달 정신병리에서 이분법적 사고의 작용을 일부 탐색할 수 있었다.

넷째, 아동의 이분법적 사고를 측정하는 척도를 개발하고 타당화 하였다. 성인에서 이분법적 사고의 작용은 비교적 활 발히 연구되고 있는데 반해(Hwang, 2007; Ko \& Hwang, 2012) 아동 및 청소년의 이분법적 사고와 관련된 연구는 부족하다. 아동의 이분법적 사고가 미치는 극단적인 영향에도 불구하고 국내에서 이분법적 사고에 관한 연구는 미비한 실정이다. 이 는 유용하고 간편한 자기보고척도의 부재 때문일 수 있다. 따 라서 개발된 아동의 이분법적 사고 지표를 통해 아동의 인지 왜곡을 측정하고, 적합한 인지 치료적 개입을 계획할 수 있는 
기반을 마련할 수 있다.

다섯째, 아동의 문제행동에 대한 인지치료적 개입을 탐색 하였다. 이분법적 사고는 정서와도 상관이 있어서, 내적 상태 의 극단적인 해석방식으로서 이분법적 사고는 정서기복의 기 제가 된다(Mansell, 2007). 대학생 대상의 연구에서 이분법적 사고는 정서의 가변성을 초래함으로서 정서적 불안정성의 배 후기제로 작용한다(Hwang, 2018). 아동의 이분법적 사고 역시 우울 및 불안과 유의한 상관을 보여 이분법적 사고가 아동의 정서조절에도 영향을 미칠 것임을 예측 할 수 있다. 아동기의 정서조절의 어려움은 다양한 문제행동으로 이어질 수 있는데, 그 중 하나로 공격성과 유의한 상관관계를 나타냈다(Y. K. Lee, 2015). 이분법적 사고가 가져오는 정서조절의 어려움은 성인 에서는 주로 내적인 고통으로 나타나지만, 정서를 다루는 데 미숙한 아동에서는 외현화된 공격성으로 이어질 수 있다. 따 라서 정서조절의 어려움으로 인한 아동문제행동의 치료계획 에서 이분법적 사고를 교정하는 인지적 개입이 효과적인 치료 전략이 될 수 있다

본 연구의 제한점과 후속 연구를 위한 제안은 다음과 같다. 첫째, 본 연구의 척도측정 가능 연령은 초등학생 4-6학년이다. 인지왜곡을 측정하는 척도제작을 위해 $\mathrm{CBT}$ 를 적용할 수 있는 연령을 선별하였으며(Verduyn, 2000), 아동의 인지발달과정을 통해 이분법적 사고가 미성숙한 인지왜곡으로서 여겨지는 구 체적 조작기 이후를 대상으로 선정하였다. 전조작기에서 구체 적 조작기 사이에 해당하는 초등학교 저학년의 경우 이분법적 사고가 자연스럽게 나타날 수 있고, 이는 인지 왜곡이라기보 다는 인지발달의 과정에서 보이는 판단 양식일 수 있다. 이에 본 척도는 초등학생 전학년을 대상으로 측정할 수 없는 척도 라는 제한점을 가진다.

둘째, 척도의 타당화 과정에서 요인별 낮은 신뢰도를 얻게 된 점도 본 연구가 지닌 한계이다. 연구대상의 발달단계상 주 된 삶의 경험이 학교에서 일어나므로, 학업성취와 관련된 요 인에 많은 문항들이 포함되었다. 그 결과 요인별로 문항의 수 가 적절하게 분배되지 않아 적은 문항으로 측정되는 '편 가르 기'와 ‘어휘상의 이분법적 사고'에서 다소 낮은 신뢰도를 나타 냈다. 이에 두 요인의 문항수를 추가할 필요가 있다. 그러나 초 등학생을 대상으로 한 척도연구에서는 응답해야 할 질문지의 문항수가 많아지면 설문 참여 동기와 주의력에 문제를 가져올 수 있다(Y. Lee \& Kim, 2009). 따라서 추후에 적절한 문항 수 추 가와 요인별 고른 분배가 이루어질 필요가 있다.

셋째, 이분법적 사고의 측정에 집중하였지만 이분법적 사 고 형성에 영향을 주는 근본적인 문제에 접근하지 못했다. 어
렸을 적 경험을 통해 형성된 비합리적 신념은 인지왜곡에 영 향을 미친다(Seo, 2009). 마찬가지로 부모의 양육태도 및 애착 정도가 아동의 이분법적 사고와 맺는 상관이나 영향력을 살펴 본다면 좀 더 근원적인 접근이 가능할 것이다. 아동의 이분법 적 사고가 인지왜곡으로 자리 잡게 된 다양한 경로를 탐색해 볼 필요가 있다.

이러한 제한점에도 불구하고 본 연구는 아동을 대상으로 이분법적 사고를 측정하는 자기보고척도를 개발하여 추후 연 구의 접근로를 열었다는 점에서 의의가 있다. 다양한 발달정 신병리의 취약성으로서 이분법적 사고가 탐색된다면 아동문 제행동의 발생과 유지 기제에 효과적으로 접근 할 수 있을 것 이다. 이분법적 사고가 관여하는 다양한 발달정신병리에서 인 지적 개입을 계획하고 적용하는 출발점이 될 것을 기대할 수 있다.

\section{Notes}

This article is based on a part of the first author's master's thesis from Hanyang Cyber University (2018).

\section{Conflict of Interest}

No potential conflict of interest relevant to this article was reported.

\section{References}

\section{In English}

Arntz, A. (1994). Treatment of borderline personality disorder: A challenge for cognitive-behavioral therapy. Behaviour Research and Therapy, 32(4), 419-430. doi:10.1016/00057967(94)90005-1

Beck, A. T., Freeman, A., \& Associates. (1990). Cognitive therapy of personality disorders. New York: Guilford Press.

Beck, A. T., Rush, A. J., Shaw, B. F., \& Emery, G. (1979). Cognitive therapy of depression. New York: Guilford Press.

Beck, A. T., Weissman, A., Lester, D., \& Trexler, L. (1976). Classification of suicidal behaviors: II. Dimensions of suicidal intent. Archives of General Psychiatry, 33(7), 835-837. doi:10.1001/archpsyc.1976.01770070065006 
Benowitz-Fredericks, C. A., Garcia, K., Massey, M., Vasagar, B., \& Borzekowski, D. L. G. (2012). Body image, eating disorders, and the relationship to adolescent media use. Pediatric Clinics of North America, 59(3), 693-704. doi:10.1016/j.pcl.2012.03.017

Byrne, S. M., Cooper, Z., \& Fairburn, C. G. (2004). Psychological predictors of weight regain in obesity. Behavior Research and Therapy, 42(11), 1341-1356. doi:10.1016/ j.brat.2003.09.004

Cohen, D. L., \& Petrie, T. A. (2005). An examination of psychosocial correlates of disordered eating among undergraduate women. Sex Roles, 52(1-2), 29-42. doi:10.1007/s11199-005-1191-x

Dyck, M. J. (1992). Subscales of the dysfunctional attitude scale. British Journal of Clinical Psychology, 31(3), 333-335. doi:10.1111/j.2044-8260.1992.tb01001.x

Egan, S. J., Piek, J. P., Dyck, M. J., \& Rees, C. S. (2007). The role of dichotomous thinking and rigidity in perfectionism. Behaviour Research and Therapy, 45(8), 1813-1822. doi:10.1016/ j.brat.2007.02.002

Epstein, S., \& Meier, P. (1989). Constructive thinking: A broad coping variable with specific components. Journal of Personality and Social Psychology, 57(2), 332-350. doi:10.1037//00223514.57.2.332

Hammond, W. A., \& Romney, D. M. (1995). Cognitive factors contributing to adolescent depression. Journal of Youth and Adolescence, 24(6), 667-683. doi:10.1007/bf01536950

Linehan, M. M. (1993). Dialectical behavior therapy for treatment of borderline personality disorder: Implications for the treatment of substance abuse. In L. S. Onken, J. D. Blaine, \& J. J. Boren (Eds.), NIDA research monograph. Vol. 137. Behavioral treatments for drug abuse and dependence (pp. 201-216). Rockville, MD: Department of Health Services and Human Services, Public Health Service, \& National Institutes of Health.

Litinsky, A. M., \& Haslam, N. (1998). Dichotomous thinking as a sign of suicide risk on the TAT. Journal of Personality Assessment, 71(3), 368-378. doi:10.1207/s15327752jpa7103_6

Mansell, W. (2007). An integrative formulation-based cognitive treatment of bipolar disorders: Application and illustration. Journal of Clinical Psychology, 63(5), 447-461. doi:10.1002/ jclp.20369

Napolitano, L. A., \& MaKay, D. (2007). Dichotomous thinking in borderline personality disorder. Cognitive Therapy and Research, 31(6), 717-726. doi:10.1007/s10608-007-9123-4

Piaget, J. (1952). The origins of intelligence in children (M. Cook, Trans.). New York: W W Norton \& Co. doi: $10.1037 / 11494-000$

Teasdale, J. D., Scott, J., Moore, R. G., Hayhurst, H., Pope, M., \& Paykel, E. S. (2001). How does cognitive therapy prevent relapse in residual depression? Evidence from a controlled trial. Journal of Consulting and Clinical Psychology, 69(3),
347-357. doi:10.1037//0022-006x.69.3.347

Verduyn, C. (2000). Cognitive behaviour therapy in childhood depression. Child and Adolescent Mental Health, 5(4), 176180. doi:10.1017/s1360641700002379

\section{In Korean}

Bae, J.-H. (2014). A study on cognitive distortion, depression, and school function for school-age children. The Journal of Korean Society of Occupational Therapy, 22(2), 65-75.

Cho, S. C., \& Lee, Y. S. (1990). Development of the Korean form of the Kovacs' childeren's depression inventory. Journal of the Korean Neuropsychiatric Association, 29(4), 943-956.

Ginsburg, H. P., \& Opper, S. (2006). Piaget's theory of intellectual development (J. Kim, Trans.). Seoul: Hakjisa. (Original work published 1988)

Hong, S. (2000). The criteria for selecting appropriate fit indices in structural equation modeling and their rationales. Korean Journal of Clinical Psychology, 19(1), 161-177.

Hwang, S. (2007). The role of dichotomous thinking in psychopathology (Doctoral dissertation). Retrieved from http://www.riss.kr/ link?id=T11059623

Hwang, S. (2009). A preliminary correlation study of the relationship between dichotomous thinking and psychopathology. Journal of Sustainability Research, 3(1), 133-149.

Hwang, S. (2013). Relation between mood shuttle and dichotomous thinking in college students with bipolar symptoms. The Korean Journal of Clinical Psychology, 32(4), 895-916. doi:10.15842/kjcp.2013.32.4.009

Hwang, S. (2018). Dichotomous thinking behind mood variability. Cognitive Behavior Therapy in Korea, 18(2), 177-197.

Hwang, S., \& Lee, H.-J. (2009). The relationship between dichotomous thinking and psychopathology. The Korean Journal of Clinical Psychology, 28(1), 1-14. doi:10.15842/ kjcp.2009.28.1.001

Hwang, S., \& Lee, H.-J. (2011). The influence of dichotomous thinking on intensity and variability of mood and self-esteem. Korean Journal of Psychology: General, 30(4), 959-972.

Hwang, S., \& Lee, H.-J. (2012). The role of dichotomous thinking in college students with panic attacks. Korean Journal of Psychology: General, 31(4), 1139-1155.

Jeong, Y.-W. (2010). The effects of cognitive-behavioral anger control program on the aggression and emotional strengths for elementary school students (Master's thesis). Retrieved from http://www.riss.kr/link?id=T11977794

Joe, S., \& Choi, J. (1989). Development of the Korean form of the state-trait anxiety inventory for children. Korean Journal of Public Administration, 14(3), 150-157

Joe, S. J., \& Doh, H.-S. (2018). The development and validation of a school adjustment scale for late school-aged children. 
Korean Journal of Child Studies, 39(2), 95-111. doi:10.5723/ kjcs.2018.39.2.95

Kang, H.-M. (2010). Dichotomous thinking and unidimensional thinking in young adults with borderline personality disorder features (Master's thesis). Retrieved from http://www.riss.kr/ link?id=T12130160

Ko, Y., \& Hwang, S. (2012). Comparison of dichotomous thinking scales on prediction of psychopathology. Cognitive Behavior Therapy in Korea, 12(2), 161-182.

Lee, H.-J., \& Won, H. (1995). Self-concepts and paranoid tendency. Psychological science, 4(2), 15-29.

Lee, J. Y. (2014). The relationship between dichotomous thinking and affect intensity: The mediating effect of nonadaptive-emotionregulation strategies (Master's thesis). Retrieved from http:// www.riss.kr/link?id=T13476376.

Lee, S. Y. (2007). Relationships of self-esteem and narcissism with aggression among Korean adolescents (Master's thesis). Retrieved from http://www.riss.kr/link?id=T11220356

Lee, Y., \& Kim, S.-H. (2009). Development of a care scale for elementary school students. The Korea Journal of Counseling, 10(4), 2479-2493. doi:10.15703/kjc.10.4.200912.2479

Lee, Y. K. (2015). The influences of children's anger on depression and aggression: Moderating effects of anger coping style and selfesteem (Doctoral dissertation). Retrieved from http://www. riss.kr/link?id=T13640867

Park, S. (2017). The effect of dichotomous thinking on interpretation of social situation (Master's thesis). Retrieved from http:// www.riss.kr/link?id=T14437807

Seo, S. (2009). The mediational roles of primary and secondary anger-thoughts between irrational beliefs and aggression.
The Korean Journal of Clinical Psychology, 28(3), 695-708. doi:10.15842/kjcp.2009.28.3.003

Seo, W., Lee, S., Kim, M., \& Kim, J. (2018). Exploratory factor analysis in psychological research: Current status and suggestions for methodological improvements. Journal of Institute for Social Sciences, 29(1), 177-193. Retrieved from http://www.riss.kr/link?id=A105082948

Seong, T. (2002). Tadangdowa silloedo [타당도와 신뢰도](2nd ed.). Seoul: Hakjisa.

Yoon, H., \& Ryu, N. (2007). Effects of family function, social support and self-esteem on elementary school children's problem behavior. Korean Journal of Social Welfare Studies, 33, 215-236.

Yun, M. H. (2014). The Relationships among dichotomous thinking, dysfunctional perfectionism and suicide ideation in adolescentsThe mediating role of hopelessness depression symptom (Master's thesis). Retrieved from http://www.riss.kr/ link?id=T13373671

\section{ORCID}

Seon Yeop Kim

Seong-hoon Hwang http://orcid.org/0000-0002-8325-2056

https://orcid.org/0000-0001-9904-174X
Received August 12, 2018

Revision received November 11, 2018

Accepted January 14, 2019 